\title{
Judicialização, ativismo e direitos fundamentais: a garantia dos pressupostos essenciais ao processo democrático pelas cortes constitucionais
}

\section{JUDICIALIZATION, ACTIVISM AND FUNDAMENTAL RIGHTS: THE WARRANTY OF ASSUMPTIONS ESSENTIAL TO THE DEMOCRATIC PROCESS FOR CONSTITUTIONAL COURTS}

\author{
Emerson Affonso da Costa Moura *
}

Resumo: O papel exercido pelo ativismo judicial na preservação da dignidade da pessoa humana e garantia das condições para exercício do princípio democrático em um contexto de judicialização das questões políticas e sociais e déficit de legitimidade e representatividade das instâncias democráticas é o tema colocado em debate. Investiga-se, em que medida, a concretização dos bens e prestações pelo Poder Judiciário, necessárias à fruição de um núcleo mínimo dos direitos fundamentais, é capaz de contribuir na tutela da cláusula geral da dignidade da pessoa humana e na realização dos pressupostos materiais necessários ao debate democrático.

Palavras-chaves: Judicialização; Ativismo; Direitos Fundamentais; Mínimo Existencial; Democracia.

Abstract: The role played by judicial activism in preserving the dignity of the human person and for guarantee the conditions to exercising the democratic in a context of political and social judicialization and deficit of legitimacy and representativeness of democratic institutions is the subject of much debate. Investigates to what extent, how the achievement of goods and services by the Judiciary necessary for the enjoyment of a minimum core of fundamental rights is able to contribute to the protection of the general clause of the dignity of the human person and the achievement assumptions materials required to democratic debate.

Keywords: Judicialization; Activism; Fundamental Rights; Minimum Existential; Democracy.
* Emerson Affonso da Costa
Moura: Mestre em Direito
Constitucional pela Universi-
dade Federal Fluminense (UFF).
É professor de Direito na Ma-
gistratura do Estado do Rio de
Janeiro (EMERJ) e Escola Su-
perior de Advocacia (ESA/
OAB). Pesquisador no Grupo
"Jurisdição Constitucional” da
Universidade Federal
Fluminense (UFF). Advogado
no Rio de Janeiro.
emersonacmour@@yahoo.com.br 


\section{INTRODUÇÃO}

A promulgação da Constituição Brasileira de 1988 com uma crescente incorporação de matérias políticas e sociais, aliada ao déficit crrescente das instâncias democráticas conduziu a uma judicialização das principais questões da sociedade e a ampliação do papel do Poder Judiciário na concretização dos valores e fins constitucionais.

Embora represente um grande potencial na concretização dos direitos fundamentais não devemos ignorar os limites da norma constitucional, a existência dos excessos, bem como, o risco da consolidação de uma hegemonia judicial ou o perigo do exercício de preferências políticas.

Neste tocante, busca a pesquisa verificar em que medida o papel exercido pelo ativismo judicial na proteção dos direitos fundamentais é capaz de garantir a preservação da dignidade da pessoa humana e garantir os pressupostos materiais para exercício do processo democrático.

Propõe-se na inevitável tensão entre constitucionalismo e democracia, a delimitação dentro do arranjo institucional brasileiro, de uma justa medida no controle exercido pelo Poder Judiciário capaz de garantir a realização dos direitos fundamentais pelos poderes públicos na forma que necessários ao funcionamento do próprio princípio democrático.

De início, a investigação se concentra no fenômeno de judicialização, de forma a definir a partir das transformações promovidas pelo constitucionalismo contemporâneo, o processo de ascensão político-institucional e ampliação do papel das cortes constitucionais nas decisões das questões políticas e sociais.

Procura-se compreender, em que medida, o reconhecimento da força normativa da Constituição, a posição de centralidade ocupada pelos direitos fundamentais na ordem jurídica, a expansão da jurisdição constitucional e o processo de ampla disciplina de matérias políticas e sociais resultam na subtração dessas questões do processo democrático.

Após, o estudo se volta à compreensão do ativismo judicial mediante sua correlação com o déficit de representatividade das instâncias democráticas que produz um distanciamento dos órgãos políticos e sociedade e desloca o exercício da cidadania para o Poder Judiciário que passa a atuar ativamente na concretização dos valores e fins constitucionais.

Tende-se a verificar, de que maneira, a redução da deliberação política ao processo eletivo, a perniciosa influência econômica sobre o eleitor, a captação dos agentes políticos pelos grupos de interesses e as deficiências do processo 
legislativo, geram a transferência da reinvidicação das demandas sociais da deliberação política para as cortes judiciais.

Por fim, o trabalho busca delimitar o conteúdo das prestações necessárias a fruição dos direitos fundamentais garantidas pelo Poder Judiciário capaz de garantir não apenas a preservação da dignidade da pessoa humana, mas de resguardar os pressupostos necessários ao processo democrático em um contexto deliberativo.

Objetiva-se determinar, de que modo, a posição ativista das cortes judiciais na concretização do núcleo essencial dos direitos fundamentais é capaz de garantir a autonomia e igualdade no debate democrático, não violando a separação dos poderes, mas racionalizando e legitimando as decisões políticas.

Para tanto, utiliza-se por metodologia a crítica dialética com apoio na doutrina pátria e estrangeira através dos principais expoentes do direito constitucional com primazia dos autores nacionais, bem como, a análise de algun julgamentos do Supremo Tribunal Federal com fins de ilustração da operatividade do debate acadêmico no âmbito das cortes judiciais.

\section{JUDICIALIZAÇÃO POLÍTICA E SOCIAL}

Com o término da segunda guerra mundial na Europa e o advento do processo de redemocratização do Brasil ascendem os pilares fundamentais que marcam o advento de um constitucionalismo contemporâneo, que consolida mudanças na compreensão do Direito no campo da dogmática, teoria e prática jurídica, sendo designado neoconstitucionalismo ${ }^{1}$.

Compreende o rompimento da concepção da Constituição como um mero documento político que veicula convite à atuação do Estado, mas o reconhecimento de sua força normativa e a atribuição do status de norma jurídica, delimitando limites e impondo deveres de atuação para os poderes públicos ${ }^{2}$.

Com a supremacia axiológica da lei fundamental e o novo status assumido pelas normas constitucionais, deriva um processo de apreensão do sistema sob

\footnotetext{
${ }^{1} \mathrm{O}$ fenômeno se notabiliza na Europa no campo normativo com a promulgação da Lei Fundamental de Bonn na Alemanha e a Constituição na Itália e no Brasil com a promulgação da Constituição da República de 1988. Sobre o tema: (CARBONELL, 2003, p. 9)

${ }^{2}$ A norma constitucional não tem existência autônoma em face da realidade, mas tão pouco se limita ao reflexo das condições fáticas: sua essência reside na pretensão de eficácia, de sua concretização na realidade imprimindo-lhe ordem e conformação. (HESSE, 1991, p 14-15).
} 
a ótica da Constituição com o objetivo de realizar os bens e valores fundamentais por ela veiculados, em um processo de constitucionalização do Direito ${ }^{3}$.

Abrange a posição de centralidade assumida pelos direitos fundamentais no sistema jurídico, com reconhecimento de sua dimensão objetiva, instutindo uma ordem de valores e irradiando a sua normatividade por todo o ordenamento, condicionando a interpretação das normas e institutos dos ramos do Direito e vinculando a atuação dos poderes públicos ${ }^{4}$.

Oriundos de uma experiência constitucional marcada por uma inflação legislativa e uma insinceridade normativa ${ }^{5}$, onde as Constituições garantistas tutelavam as liberdades formais como repositórios de promessas vagas, a veiculação de amplo elenco de direitos fundamentais e a sua vedação ao poder de reforma, reforçou a rigidez da Constituição.

Envolve a ampliação do elenco de legitimados para a propositura das ações de controle de constitucionalidade e a criação de novos instrumentos de controle concentrado, garantindo a preservação dos direitos fundamentais do processo político majoritário reservando sua tutela ao Poder Judiciário ${ }^{6}$.

Mediante a expansão da jurisdição constitucional garante-se a proteção da lei fundamental com a preservação de sua hierarquia formal e axiológica perante as normas infraconstitucionais, bem como, atos dos demais poderes, mediante atuação das cortes constitucionais ${ }^{7}$.

Por fim, inclue o processo de ampla disciplina de matérias políticas e sociais, que antes sujeitas ao campo da legislação deslocam-se para a esfera da Constituição se submetendo apenas a regulamentação pelas normas

\footnotetext{
${ }^{3}$ A força irradiante da Constituição, portanto, não se limitou apenas à reconstrução dinâmica de seus próprios enunciados de norma numa espécie previsível de auto-alimentação constitutiva, mas se projetou para todo o sistema jurídico, revisando o sistema de fontes e reestruturando seus pilares deontológicos. (SAMPAIO, 2007, p. 200).

${ }^{4}$ Os direitos fundamentais possuem, portanto, uma dupla ordem de sentido: como vínculos axiológicos, que condicionam a validade material das normas produzidas e enquanto fins que orientam o Estado Constitucional de Direito. (FERRAJOLI, 1999, p. 22).

${ }^{5}$ Não foi incomum a existência formal de Constituições que invocaram o que não estava presente, afirmavam o que não era verdade e prometiam o que não seria cumprido. Como e.g. tem-se a Constituição de 1969 que garantia os direitos à integridade física e a vida, com as prisões ilegais, a tortura e o desaparecimento de pessoas na ditadura. (BARROSO, 2003, p. 61).

${ }^{6}$ Insere-se, portanto, o exercício da jurisdição constitucional orgânica e das liberdades no complexo de mecanismos de natureza normativa, institucional ou processual tendentes a assegurar a plena realização dos direitos fundamentais. (COELHO, 2005, p. 34).

${ }^{7}$ No Brasil amplia-se o objeto e escopo da jurisdição constitucional através da ampliação do elenco de legitimados ativos para a propositura da ação direta de inconstitucionalidade (artigo 103 inciso I a

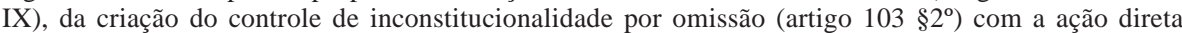
e o mandado de injunção (artigo 102 “q”), da previsão da argüição de descumprimento de preceito fundamental (artigo102 $\S 1^{\circ}$ ) dentre outros.
} 
infraconstitucionais, garantindo maior segurança e estabilidade jurídica em face das ingerências fugazes dos poderes constituídos ${ }^{8}$.

Com a previsão exaustiva dos bens e interesses sociais na lei fundamental e a respectiva subtração das questões da vida política e social do alcance do legislador, essas passaram a encontrar fundamentos imediatos nas normas constitucionais sujeitando-se ao controle de adequabilidade dos atos legislativos e administrativos com a lei fundamental.

Esses novos paradigmas importam um novo papel das cortes judiciais na promoção dos valores constitucionais, que aliado ao acréscimo da demanda social por justiça e a recuperação das garantias institucionais, resulta na ascensão político-institucional do Poder Judiciário e na expressiva judicialização das questões políticas e sociais.

No vértice da ascensão político-institucional do Poder Judiciário, a recuperação das liberdades democráticas e das garantias institucionais dos membros da magistratura com a redemocratização brasileira, permitiram um campo de independência e imparcialidade na aplicação do direito vigente e na interpretação das normas constitucionais ${ }^{9}$.

No campo da judicialização, as questões políticas e sociais que aprioristicamente estariam sujeitas ao campo do processo político majoritário e exteriorizadas na conformação legislativa e discricionariedade administrativa passam a ser decididas pelo Poder Judiciário na preservação da supremacia da Constituição e dos bens e valores por ela veiculados ${ }^{10}$.

É aferida através da atribuição aos órgãos de controle de constitucionalidade da resolução de conflitos de competência relativo ao exercício do poder estatal, do controle do exercício da conformação legislativa

\footnotetext{
${ }^{8}$ Surge no pós-guerra na Europa como reação aos governos nazistas e facistas e a desconfiança da democracia em massa que fizeram surgir substantivas cartas de direito e potentes tribunais constitucionais. No Brasil há enorme ambição do texto constitucional de 1988 em um compromisso com as transformações sociais e a concentração de poderes na esfera de jurisdição do Supremo Tribunal Federal. (VIEIRA, 2008, p. 443-444).

${ }^{9}$ Com a redemocratização ampliou-se a demanda por justiça na sociedade brasileira, pela redescoberta da cidadania e conscientização dos indivíduos sobre os seus direitos. Neste ambiente, os juízes passaram a desempenhar um papel simbólico no imaginário coletivo, na defesa da justiça e dos direitos. (BARROSO, 2007, p. 35).

${ }^{10}$ Toda decisão legislativa é pré-disciplinada por normas constitucionais, idôneas, portanto, a regular de forma explícita ou implícita qualquer aspecto da vida política e social. Isto importa no reconhecimento da inexistência de qualquer questão que não esteja sujeita ao controle de parametricidade com a Constituição, sem desconsiderar que existem questões de natureza política sujeitas ao princípio majoritário, porém, compreender que existem outros princípios a serem preservados na ordem constitucional. (GUASTINI, 2007, p. 276).
} 
e discricionariedade administrativa pelo Poder Judiciário e do emprego das normas constitucionais na argumentação dos atores políticos.

Como efeito observa-se um crescente exercício das ações abstratas pelos atores políticos e sociais, que amplia a influência da Constituição sobre as relações políticas, bem como, a atuação do Supremo Tribunal Federal na decisão de matérias essenciais para a sociedade.

Em um cenário de judicialização das questões políticas e sociais, bem como, de déficit de legitimidade e representatividade das instâncias democráticas, observa-se o exercício de um papel ativo das cortes judiciais na concretização dos valores e fins veiculados pela constituição, usualmente designado de ativismo judicial.

O tema é objeto de debate a seguir.

\section{ATIVISMO JUDICIAL}

O ativismo judicial corresponde a uma atuação intensa e ativa do Poder Judiciário em questões políticas e sociais que caberiam precipuamente aos demais poderes, de forma a garantir a concretização dos valores e fins veiculados pelas normas constitucionais e preservar a supremacia axiológica e formal da Constituição ${ }^{1112}$.

Sua origem é apontada no início do século XX com as decisões da Suprema Corte dos Estados Unidos ${ }^{13}$ e a partir da década de 1950 do Tribunal

${ }^{11}$ O termo ativismo judicial foi empregado pela primeira vez em 1947 pelo historiador e político Arthur Schlesinger Jr. em artigo na revista Fortune, todavia, não há um consenso sobre a sua definição, adotando alguns autores um critério quantitativo - para definir como a atuação demasiada do Poder Judiciário nas decisões dos demais poderes - e outros um critério qualitativo - de forma minimalista ou maximalista - na concretização dos valores constitucionais, que adotamos neste trabalho. Sobre o tema vide: (DIMOULIS; LUNARDI, 2011. p. 460-464).

${ }^{12}$ Como visto, não sendo a judicialização uma opção política do Poder Judiciário, mas uma decorrência do desenho institucional vigente, uma vez provocados em razão do princípio da inafastabilidade da tutela jurisdicional cabe aos juízes e tribunais se manifestarem, todavia, o modo como venham a exercer essa competência é que importará em um ativismo judicial - na concretização dos valores e fins constitucionais em atenção a supremacia axiológica da constituição - ou em uma autocontenção judicial - na preservação do ato legislativo ou administrativo em atenção ao princípio democrático, razão pelo qual, não se confunde judicialização das questões políticas e sociais com ativismo judicial. ${ }^{13}$ Inicialmente o ativismo judicial foi utilizado de forma conservadora permitindo a legitimidade para a segregação racial (Dred Scott vs. Sanford em 1857) e invalidação e leis sociais (Lockner v. New York em 1905), porém, no período de 1953 e 1969 sob a presidência de Earl Warren oram tomadas as decisões progressistas em matéria de direitos fundamentais, como em relação a segregação racial nas escolas públicas (Brown vs. Board of Education em 1954), a incriminação do uso de pílulas anticoncepcionais (Griswold vs. Connecticut em 1965) entre outras. Sobre o tema vide: (BARROSO, 2009, p. 144). 
Constitucional Alemão e Italiano ${ }^{14}$ na tutela dos direitos fundamentais, se notabilizando no Brasil nos últimos anos com decisões sobre importantes questões políticas e sociais pelo Supremo Tribunal Federal ${ }^{15}$.

Envolve a aplicação direta e imediata da Constituição em situações não expressamente contempladas no texto constitucional, diante de omissão ou violação por disciplina normativa pelo legislador ou ato concreto do administrador, com vistas à garantia de proteção ou concretização dos valores e fins constitucionais ${ }^{16}$.

Abrange a invalidação de atos normativos emanados do Poder Legislativo ou Administrativo de constitucionalidade discutível, ou seja, com adoção de critérios menos rígidos do que aqueles onde inexiste patente e ostensiva violação da Constituição, com vista à preservação da hierarquia das normas

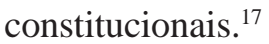

Por fim, compreende a imposição de condutas ou de abstenções ao Poder Público capazes de impedir violação ou garantir a concretização de direitos e fins constitucionais, em especial, mediante o controle judicial sobre os programas de políticas públicas de forma a assegurar o acesso a prestações a bens e serviços essenciais. ${ }^{18}$

${ }^{14}$ Na Alemanha, o Tribunal Constitucional fixou que a lei fundamental não era ordem neutra de valores, mas que consagrava uma ordem objetiva instrumental à garantia dos direitos fundamentais (BVerfGE7, 198 (205). Porém, assim como na Itália, tentou suavizar os impactos políticos da sua decisão, como, por exemplo, advertindo sobre as suas omissões para a sua correção ou advertindo sobre uma revogação em caso de não atuação legislativa retificadora. Sobre o tema, vide: (VALLE, 2009, p. 28).

${ }^{15}$ A título exemplificativo, podemos citar, algumas decisões do Supremo Tribunal Federal que denotam um ativismo judicial: a fidelidade partidária, a vedação do nepotismo, a verticalização as coligações partidárias e cláusula de barreira, o direito a greve no serviço público dentre outros.

${ }^{16}$ Como, por exemplo, no caso das uniões homoafetivas (ADPF 132) onde inexiste regra constitucional expressa que tutele as relações ou prescreva a aplicação do regime de união estável, bem como, não há vedação da norma do artigo $226 \S 3^{\circ}$ que ao tratar de homem e mulher buscou a superação da desigualdade na relação de casamento e não impedir a aplicação do regime às uniões homoafetivas. Neste sentido, o Supremo Tribunal Federal com fundamento na dignidade da pessoa humana aplicou o regime das uniões estáveis a essa nova modalidade de família. Sobre o tema, vide: (BARROSO, 2008, p. 155).

${ }^{17}$ Como, por exemplo, no caso da verticalização (ADIn 3685) onde o artigo $2^{\circ}$ da Emenda Constitucional 52 de 8 de Março de 2006 alterava o artigo $17 \S 1^{\circ}$ da Constituição da República, fixando data para alteração, em violação ao princípio da anterioridade anual da lei eleitoral (CF, art. 16). O Supremo Tribunal Federal para proteger a norma constitucional, que embora não tivesse uma violação frontal perderia sua eficácia, declarou inconstitucional a emenda constitucional dando a norma do artigo 16 o status de cláusula pétrea embora não se enquadre ao rol de cláusulas elencadas na Constituição. Sobre este tema consulte-se: (GALLACCI, 2011, p. 25-27).

${ }^{18}$ Como, por exemplo, as ações judiciais relativas à concretização de prestações necessárias a fruições de direitos sociais (alimentação, saúde e moradia...) concedidas pelos órgãos do Poder Judiciário como, por exemplo, a distribuição de medicamentos e determinação de terapia. O Supremo Tribunal Federal na ADPF 45/DF se manifestou, no sentido, que não obstante a formulação e a execução das 
No Brasil o ativismo judicial está diretamente relacionado com a crise de legitimidade e representatividade democrática, que gera um descolamento entre os órgãos representativos e a sociedade, e a incapacidade ou desinteresse em atender as demandas sociais, produzindo um deslocamento do exercício da cidadania para o âmbito do Poder Judiciário.

A redução da deliberação política ao processo eletivo ${ }^{19}$, a histórica e perniciosa influência econômica dos agentes políticos sobre o eleitor ${ }^{20}$ e a captação dos agentes políticos por grupos de interesse ${ }^{21}$, conduz a um distanciamento entre representante e representando promovendo estreitamento do debate político que se transfere para os órgãos judiciários.

O desinteresse dos atores políticos em atender questões de interesse social onde há um desacordo moral razoável na comunidade, de forma a evitar os desgastes promovidos pelo debate e os riscos da responsabilização política nas eleições, tornam o Poder Judiciário uma instância decisória política de questões polêmicas ${ }^{22}$.

O processo de hipertrofia legislativa com a explosão de legislação infraconstitucional e regulamentação infralegal, bem como, a atecnicidade da produção legislativa com a criação de conceitos jurídicos indeterminados

políticas públicas dependam de opções políticas a cargo daqueles que, por delegação popular, receberam investidura em mandato eletivo, cumpre reconhecer que não se revela absoluta, neste domínio, a liberdade de conformação do legislador, nem a de atuação do Poder Executivo, de modo que não podem proceder com a clara intenção de neutralizar, comprometendo-a, a eficácia dos direitos sociais, econômicos e culturais. Sobre o tema, em seus limites e possibilidades, vide: (MOURA, 2011).

${ }^{19}$ Trata-se de fenômeno com fundamentos diversos, que variam desde a impossibilidade de participação devido às condições de pobreza extrema e baixo nível de educação de grande parte da população, da dificuldade de acesso às informações sobre as questões políticas e a falta de tempo para debater e manifestar sobre tais assuntos, até mesmo a descrença de que sua participação seja capaz de influenciar na ação pública. (BARCELLOS, 2008, p. 82-84).

${ }^{20}$ Remonta ao período colonial brasileiro a adoção de um modelo patrimonialista marcado pelo predomínio da corrupção, nepotismo e uso do poder econômico que se exterioriza até os dias atuais na corrupção persistente e nas políticas paternalistas que marcam a política brasileira. Sobre o tema, vide: (FAORO, 2000; FREYRE, 2000 e NUNES, 1997).

${ }^{21}$ A captura de partidos e candidatos por grupos de interesse que patrocinam as campanhas eleitorais para posteriormente cobrar favores, por meio da satisfação de políticas distributivas a seu favor é uma das formas de captura, mas não único meio de influência dos grupos de interesse, em especial, econômicos, na captura dos membros do Congresso. Sobre o tema, vide: (MANCUSO, 2007. p. 110).

${ }^{22}$ Dentre outros fatores, o ativismo judicial é exercido em contextos de inércia intencional pelos demais poderes de Estado. Em casos que são politicamente custosos com temas profundamente custosos sem perspectiva de consenso na sociedade, como as uniões homoafetivas, abertura dos arquivos da ditadura militar e aborto, as instâncias democráticos abrem espaço para atuação ativista repassando os custos políticos para os tribunais que não passam pelo crivo do voto popular após suas decisões. (VIEIRA; CAMARGO, 2009. p. 44-45). 
desencadeiam a ampliação dos conflitos na sociedade e litigiosidade, bem como, o potencial criativo e margem de discricionariedade do Judiciário ${ }^{23}$.

As omissões legislativas na regulamentação de preceitos impostas pela Constituição que impede o exercício dos direitos pelos representados, aliado a instituição de mecanismo próprio de controle de constitucionalidade pela via concentrada e a utilização de ação constitucional na via incidental, impõe a intervenção judicial na decisão política.

Por efeito, em um cenário de crise das instâncias democráticas, o papel ativo das cortes judiciais na realização dos valores e fins constitucionais não viola o princípio da separação dos poderes, mas é capaz de contribuir com o processo democrático ao garantir os seus pressupostos materiais, pela concretização dos direitos fundamentais.

O tema é objeto de debate a seguir.

\section{DIREITOS FUNDAMENTAIS E DEMOCRACIA}

Na nossa experiência constitucional antes restrita a Constituições garantistas que tutelavam as liberdades formais como repositórios de promessas vagas, com a promulgação da Constituição de 1988 se incorpora amplo rol de direitos e garantias fundamentais e volta-se a preocupação para a aplicabilidade direta e imediata de suas normas veiculadoras ${ }^{24}$.

Interrompe-se um ciclo inicial de baixa normatividade das disposições que veicula os direitos fundamentais, em especial, das normas que declaravam os direitos sociais, antes remetidas à esfera programática de meras linhas diretoras aos poderes públicos e, tidas como dotadas de eficácia limitada.. ${ }^{25}$

Os direitos fundamentais enquanto veiculado por normas constitucionais passam a ser tidos de exequibilidade plena, e como dependem para seu exercício

\footnotetext{
${ }^{23}$ A hipertrofia do direito legislado e a produção de leis vagas reforçam e alimentam a possibilidade do direito judicial transferindo para o Poder Judiciário a decisão sobre conflitos que caberiam ser dirimidos no âmbito político. (CAMPILONGO, 2000. p. 87).

${ }^{24}$ Não é incomum a existência formal de Constituições que invocam o que não está presente, afirmam o que não é verdade e prometem o que não será cumprido. Como, e.g., tem-se a Constituição de 1969 que garantia os direitos à integridade física e a vida, com as prisões ilegais, a tortura e o desaparecimento de pessoas na ditadura. Através da doutrina brasileira da efetividade, surge um movimento jurídico-acadêmico que procura elaborar as categorias dogmáticas da normatividade constitucional e superar dentre outras questões a insinceridade normativa que vigia no país. (BARROSO, 2007, p. 61). ${ }^{25}$ A aplicabilidade restrita das normas de natureza programática decorreria da fluidez de suas disposições e da inexistência de instrumentos jurídico-processuais capazes de garantir sua concretização. (BONAVIDES, 2003, p. 564-565). Compreendendo que as relações econômico-sociais são disciplinadas apenas por normas programáticas, vide: (SILVA, 2008, p. 140-142).
}

REVISTA DO DIREITO PÚBLICO, Londrina, v.9, n.1, p.227-244, jan./abr.2014 
de prestações positivas e negativas pelos poderes públicos, são exigíveis perante o Estado mediante a abstenção de sua violação, bem como, o oferecimento dos bens e serviços necessários à sua fruição. ${ }^{26}$

Neste tocante, a adjudicações de prestações pelo Estado com a criação e colocação à disposição de seus titulares os bens materiais e imateriais necessários à fruição dos direitos fundamentais ${ }^{27}$ ocorre através da articulação de programas de ação governamental inserto no espaço de conformação legislativa e discricionariedade administrativa. ${ }^{28}$

Todavia, é superada a tese que considera o Poder Judiciário sem competência para exercer o controle sobre as questões políticas, pois os programas de ação governamental se identificam como atos de governo, reservadas suas responsabilidades à seara democrática do processo eletivo e do controle social. ${ }^{29}$

Em um Estado Democrático de Direito, cabe a Constituição garantir as condições necessárias ao processo democrático, mediante a garantia das condições procedimentais e da reserva do espaço próprio do pluralismo político, assegurando um ambiente para o adequado funcionamento da deliberação política $^{30}$.

Porém, abrange também, a preservação de um conjunto de valores e objetivos que traduzem um compromisso com a transformação social e não permite que os poderes constituídos disponham livremente dos referidos bens,

\footnotetext{
${ }^{26}$ As normas constitucionais tenham caráter imediato ou prospectivo como regras de conduta emanadas do Estado são dotadas de eficácia jurídica. Assim, incidem e regem as situações de vida produzindo os seus efeitos próprios, e, diante da sua inobservância espontânea deflagram mecanismos de aplicação coativa. (BARROSO, 2006. p. 248 e 274).

${ }^{27}$ Em síntese, corresponderia a obrigação do Estado de: respeitar o acesso do indivíduo aos bens necessários a fruição; proteger o seu exercício perante terceiros; assistir o titular quando este não puder por si só exercê-lo; e promover as condições para que os titulares do direito tenham acesso aos bens. (ABRAMOVICH; COURTIS, 2003. p. 139-141).

${ }^{28}$ Neste ponto, há uma interpenetração da esfera política na ciência jurídica, resultante da crescente preocupação dos juristas com a realização dos direitos fundamentais, ampliando a comunicação entre estes dois subsistemas sociais: as ciências políticas e o direito. Sobre as consequências e as possíveis vantagens desta correlação, vide por todos: (BUCCI, 2002, p. 241-244).

${ }^{29}$ Os atos de governo são aqueles exercidos pelos órgãos de direção do Poder Executivo e Legislativo com finalidade de imprimir à gestão pública, os fins dos Estados, as opções de políticas públicas e orçamentárias e a direção geral da política estatal. Segundo seus adeptos, seus exercícios não lesam direito do indivíduo, razão pelo qual não se sujeitariam a controle jurídico. Neste sentido: (MORAIS, 2002. p. 529; BARBOSA, 2003. p. 118).

${ }^{30}$ A Constituição não pode e nem deve ter a pretensão de suprimir a deliberação legislativa majoritária, mas deve proteger as condições procedimentais que permitam o desenvolvimento do processo político deliberativo. Assim, a Constituição da República de 1988 veiculou o princípio democrático e majoritário (Art. $1^{\circ}$ caput), garantiu o pluralismo político (Art. $1^{\circ}$ inciso $\mathrm{V}$ ), a inserção como cláusula pétrea a tendente abolir o voto direto, secreto, universal e periódico e a forma federativa (art. $60 \S 4^{\circ}$ ) dentre outros. No viés procedimentalista vide: (ELY, 2011; HABERMAS, 1997).
} 
gerando o esvaziamento da eficácia de suas normas a título de exercício da democracia. $^{31}$

Cabe a lei fundamental veicular consensos mínimos para proteção dos indivíduos e funcionamento do regime democrático, protegendo os direitos fundamentais do exercício do princípio majoritário e das decisões proferidas por maiorias políticas ocasionais, inclusive, mediante o controle de deliberações políticas que o violem ${ }^{32}$.

No âmbito de uma democracia deliberativa, o processo democrático abrange a deliberação pública que ocorre em um contexto de livre circulação de idéias e de informações, mediante o respeito e concretização de direitos fundamentais que permitam à igualdade de condições no debate democrático, racionalizando e legitimando as decisões políticas ${ }^{33}$.

A construção de um modelo cooperativo no contexto democrático compreende a concretização de direitos fundamentais capazes de garantir a liberdade de agir e o acesso igualitário de tpdps na realização de um projeto de vida pessoal e na participação do processo de formação da vontade coletiva.

Envolve, portanto, um núcleo essencial dos direitos fundamentais a ser concretizado pelo Poder Judiciário, que seja capaz de preservar não apenas as condições mínimas para uma existência humana digna, mas de garantir os pressupostos materiais necessários para uma efetiva participação democrática.

Assim, não se restringe ao mínimo existencial, que envolve as condições fundamentais para uma vida com dignidade ${ }^{3435}$, mas envolve pressupostos

\footnotetext{
${ }^{31}$ Isto por que a ideia de democracia não se limita ao governo da maioria, porém, compreende outros princípios e o respeito aos direitos da minoria. Assim, enquanto o processo político majoritário se move por interesses, a lógica democrática se inspira em valores, restando ao Poder Judiciário preservar diante da soberania popular e governo da maioria, a limitação do poder e os direitos fundamentais. (BARROSO, 2008, p. 382-91).

${ }^{32}$ A Constituição deve proteger e as cortes judiciais implementar os direitos e princípios que realizem os valores de justiça, liberdade e igualdade. No viés substancialista vide: (RALWS, 2008; DWORKIN, Ronald. 2010).

${ }^{33}$ Para que a deliberação ocorra em efetivo, deve existir um contexto aberto, livre e igualitário, onde todos possam participar com iguais possibilidades e capacidades para influenciar e persuadir. Esses pressupostos de uma deliberação justa e eficiente são institucionalizados através do Estado de Direito e da garantia dos direitos fundamentais que são pressupostos da verdadeira democracia. Assim, quando uma corte constitucional garante os direitos fundamentais contra a vontade da maioria não estão violando o princípio democrático, mas estabelecendo as condições para a sua plena realização. (SOUZA NETO, 2009, p. 79-80).

${ }^{34}$ Neste sentido, Ana Paula de Barcellos, ao se referir ao mínimo existencial considera a distinção entre um núcleo essencial que deve ser reconhecida eficácia jurídica positiva e para além deste núcleo onde se desenvolvem outras modalidades de eficácia jurídica na preservação do espaço da política e das deliberações majoritárias. (BARCELLOS, 2009, p. 248).

${ }^{35}$ É o que ocorre, por exemplo, com a educação fundamental e a medicina preventiva e de urgência que correspondendo respectivamente ao núcleo essencial do direito à educação e saúde, poderiam ser exigidas pelos indivíduos que precisem perante o Poder Judiciário sem restrições. Já o ensino superior e o médio e a medicina curativa exorbitariam este conteúdo, razão pelo qual, dependeriam da progressiva realização pelos poderes públicos. (TORRES, 2009. p. 54, 130, 255 e 267).
} 
essenciais para o funcionamento adequado do próprio sistema jurídicodemocrático que constituem matriz irredutível, indisponível e insuscetível de restrição pelos poderes públicos e controlados pela jurisdição.

Assim, abrange a adjudicação pelo Poder Judiciário das prestações materiais necessárias à fruição do direito à liberdade e a igualdade, permitindo que o indivíduo possa exercer efetivamente sua autonomia na esfera privada e pública $^{36}$ e tenha possibilidade de participar e cooperar de forma igualitária no processo político democrático ${ }^{37}$.

\section{CONSIDERAÇÕES FINAIS}

Em um Estado Democrático de Direito a Constituição não pode ocupar todo espaço jurídico inviabilizando a expressão da soberania popular mediante a deliberação democrática ou impondo um projeto social às próximas gerações ignorando as transformações ocorridas na própria comunidade.

Embora a Constituição veicule as opções fundamentais da sociedade não deve ser utilizada como instrumento de modelagem de todos os espaços sociais, ignorando a área livre de conformação utilizada pelos agentes políticos para conduzir com a participação dos atores sociais as deliberações públicas na busca pela solução das demandas contemporâneas.

Tão pouco, em um cenário de coordenação entre os poderes estatais, de pluralismo social e de crescente complexidade da vida, a interpretação constitucional restringe-se apenas ao âmbito do processo judicial seja objetivo ou subjetivo e muito menos tem como único sujeito os órgãos judiciais.

O sistema de separação de poderes, com o epicentro em uma Constituição formal, atribui em razão da especialização funcional e independência orgânica ao Poder Legislativo e Executivo, funções cujo exercício, que ocorre de forma preponderante e sem interferência, correspondem em último grau à realização das normas constitucionais.

\footnotetext{
${ }^{36}$ Como ilustração, no que tange ao direito de educação, não envolve apenas as prestações referentes à educação fundamental, pois o ingresso nos níveis mais avançados de ensino depende da capacidade de cada um e envolve a necessária igualdade de condição, ou seja, o acesso ao Ensino Médio, permitindo que o indivíduo possa buscar um projeto razoável para a sua vida (faculdade) e seja capaz de participar da deliberação política de forma igualitária com os demais.

${ }^{37}$ A igualdade envolve, em certa medida, uma igualdade econômica e social razoável que permita que todos os indivíduos e grupos em um contexto de pluralismo tenham condições e se vejam motivados a cooperar no processo político democrático. É inverossímil sustentar que uma pessoa que não tem acesso a alimentação adequada ou a saúde curativa, bem como, um grupo hipossuficiente sem saneamento básico ou acesso a programas sociais, sejam capazes de participar do debate democrático em igual condição com os demais indivíduos e grupos.
} 
Cabem, portanto, aos poderes públicos na concretização dos preceitos fundamentais, observadas as possibilidades das regras e princípios constitucionais e limitados aos seus respectivos campos de conformação ou discricionariedade, decidirem sobre as questões políticas definindo quais são capazes de atender as necessidades do grupo social.

Isto porque no sistema representativo o campo adequado para o debate sobre a conveniência da decisão política e social é a deliberação política e do controle social através de mecanismos que variam desde a mobilização da sociedade civil na fiscalização da gestão pública até a responsabilização política através de eleições competitivas.

Isto não importa, todavia, em ignorar as deficiências do processo político majoritário e o déficit democrático das instâncias representativas que ampliam o distanciamento entre representante e representado e a incapacidade de atendimento das demandas sociais, em especial, da concretização dos direitos fundamentais.

Tão pouco, que o reconhecimento da força normativa da Constituição e o seu deslocamento para o epicentro da ordem jurídica, com a expansão da jurisdição e a dimensão objetiva dos direitos fundamentais, permitem que o Poder Judiciário invalide quando ato advindo das instâncias democráticas que viole os preceitos constitucionais.

Nesta tensão constante entre democracia e constitucionalismo cabe às cortes constitucionais resguardar o processo democrático mediante o respeito ao princípio político majoritário e as decisões dos poderes constituídos e proteger a supremacia da Constituição através da promoção dos valores e fins fundamentais veiculados pelo poder constituinte.

A Constituição assegura as regras do jogo democrático, não apenas garantindo a participação política ampla e o governo da maioria, mas também preservando um conjunto de direitos fundamentais necessários a uma existência humana digna e essencial ao debate político por garantir a participação de todos em iguais condições.

Neste tocante, a atuação ativista do Poder Judiciário na concretização de um núcleo essencial dos direitos fundamentais contribui na preservação da dignidade da pessoa humana e na garantia dos pressupostos materiais essenciais ao debate democrático, ao permitir as condições básicas para participação efetiva no processo de formação da vontade coletiva. 


\section{REFERÊNCIAS}

ABRAMOVICH, Victor; COURTIS, Christian. Apuntes sobre la exigibilidad judicial de los derechos sociales. In: SARLET, Ingo Wolfgang (org.). Direitos fundamentais sociais: estudos de direito constitucional, internacional e comparado. Rio de Janeiro: Renovar, 2003.

BARBOSA, Rui. Atos inconstitucionais. Campinas: Russell, 2003.

BARCELLOS, Ana Paula de. A eficácia jurídica dos princípios constitucionais: princípio da dignidade da pessoa humana. Rio de Janeiro: Renovar, 2002.

. Controle social, informação e Estado Federal: A interpretação das competências político-administrativas comuns. In: SOUZA NETO, Cláudio Pereira; SARMENTO, Daniel; BINENBOJM, Gustavo. Vinte anos da Constituição Federal de 1988. Rio de Janeiro: Lumen Juris, 2009.

- Papéis do Direito Constitucional no Fomento do Controle Social Democrático: Algumas Propostas Sobre o Tema da Informação in RDE ano 3. N. 12. Out/dez 2008.

BARROSO, Luís Roberto. A Reconstrução Democrática do Direito Público no Brasil in: BARROSO, Luís Roberto (Org). A Reconstrução Democrática do Direito Público no Brasil: Livro Comemorativo dos 25 anos de magistério do professor Luís Roberto Barroso. Rio de Janeiro, Renovar: 2007.

. Interpretação e aplicação da Constituição. 6. ed. Rio de Janeiro: saraiva, 2006.

. O Direito Constitucional e a Efetividade de suas Normas:

Limites e Possibilidades da Constituição Brasileira. 7 ed. Rio de Janeiro, Renovar, 2003. 
. O Reconhecimento Jurídico das Relações Homoafetivas no

Brasil. Revista do Ministério Público do RJ. n. 27.

. Neoconstitucionalismo e a Constitucionalização do Direito.

O Triunfo Tardio no Direito Constitucional no Brasil in: SARMENTO, Daniel e SOUZA NETO, Cláudio Pereira de (Orgs). A Constitucionalização do Direito: Fundamentos Teóricos e Aplicações Específicas. Rio de Janeiro: Lumen Juris, 2007.

A Americanização do Direito Constitucional e seus

paradoxos in: Temas de direito constitucional. t. IV. Rio de Janeiro: Renovar, 2009.

BONAVIDES, Paulo. Curso de direito constitucional. 13. ed. São Paulo: Malheiros, 2003.

BUCCI, Maria Paula Dallari. Direito administrativo e políticas públicas. São Paulo: Saraiva, 2002.

CAMPILONGO, Celso Fernandes. O Direito na sociedade complexa. São Paulo: Max Limonad, 2000.

CARBONELL, Miguel (Org). Neoconstitucionalismo(s). 1 ed. Madrid: Editorial Trotta, 2003.

COELHO, Rosa Júlia Plá. Mecanismos de Proteção dos Direitos Fundamentais. 1 ed. Brasília: Ordem dos Advogados do Brasil, 2005.

DIMOULIS, Dimitri e LUNARDI, Soraya Gasparetto. Ativismo e Autocontenção Judicial no Controle de Constitucionalidade in: FELLET, André Luiz Fernandes; PAULA, Daniel Grotti de. NOVELINO, Marcelo. As Novas Faces do Ativismo Judicial. São Paulo: Jus Podvim, 2011.

DWORKIN, Ronald. Levando os Direitos a Sério. Belo Horizonte: Editora Martins Fontes, 2010. 
ELY, John Hart. Democracia e Desconfiança: Uma teoria do controle judicial de constitucionalidade. São Paulo: Martins Fontes, 2011.

FAORO, Raymundo. Os Donos do Poder. 15 ed. São Paulo: Editora Globo, 2000.

FERRAJOLI, Luigi. Derechos e Garantias: La ley del mais débil. 1 ed. Madrid: Trotta, 1999.

FIGUEIREDO, Marcelo. O controle das políticas públicas pelo poder judiciário no Brasil: uma visão geral. Interesse Público. ano 9. n. 44.

FREYRE, Gilberto. Casa-grande e Senzala. 39 ed. Rio de Janeiro: Record, 2000.

GARAPON, Antonie. O Juiz e a Democracia: O Guardião de Promessas. Rio de Janeiro: Renavam, 1999.

GALLACCI, Fernando Bernardi. O STF e as Cláusulas Pétreas: O ônus argumentativo em prol da governabilidade? São Paulo: SBDP, 2011.

GUASTINI, Riccardo. A Constitucionalização do ordenamento jurídico e a experiência italiana in: SARMENTO, Daniel e SOUZA NETO, Cláudio Pereira de (Orgs). A Constitucionalização do Direito: Fundamentos Teóricos e Aplicações Específicas. Rio de Janeiro: Lumen Juris, 2007.

HABERMAS, Jurgen. Direito e democracia entre facticidade e validade. Rio de Janeiro: Tempo Brasileiro, 1997.

HÄRBELE, Peter. Hermenêutica constitucional. A sociedade aberta dos intérpretes da Constituição: contribuição para a interpretação pluralista e procedimental da Constituição. Porto Alegre: Sergio Antonio Fabris Ed., 2002.

HESSE, Konrad. A Força Normativa da Constituição. Porto Alegre: Sergio Antonio Fabris Editor, 1991. 
LOPES, José Reinaldo de Lima. Judiciário, democracia e políticas públicas. Revista de Informação Legislativa. ano 31. n. 122. Brasília: Senado Federal, maio-jul. 1994.

MANCUSO, Wagner Pralon. O Lobby da indústria no Congresso Nacional. São Paulo: EDUSP, 2007.

MORAIS, Blanco de. Justiça constitucional. Coimbra: Coimbra Ed., 2002.

MOURA, Emerson Affonso da Costa. Do Controle Jurídico ao Controle Social: Parâmetros a Efetividade dos Direitos Sociais. Revista de Direito Constitucional e Internacional, vol. 77, dez/2011.

\section{Políticas Públicas, Controle Social e Orçamento}

Participativo. Revista de Direito Tributário. Malheiros Editores. vol 114. nov/dez 2011.

NUNES, Edson. A gramática política do Brasil - clientelismo e insulamento burocrático.

PALU, Oswaldo Luiz. Controle dos atos de governo pela jurisdição. São Paulo: Ed. RT, 2004.

QUEIROZ, Cristina M. M. Os actos políticos no Estado de Direito - O problema do controle jurídico do poder. Coimbra: Almedina, 1990.

RALWS, John. Uma Teoria de Justiça. Belo Horizonte: Editora Martins, 2008.

SAMPAIO, José Adércio Leite. Mito e História da Constituição:

Prenúncios Sobre a Constitucionalização do Direito in: SOUZA NETO, Cláudio Pereira e SARMENTO, Daniel. A Constitucionalização do Direito: Fundamentos Teóricos e Aplicações Específicas. Rio de Janeiro: Lumen Juris, 2007.

SARMENTO, Daniel. "O Neoconstitucionalismo no Brasil: Riscos e possibilidades”. In: Daniel Sarmento (Org.). Filosofia e Teoria Constitucional Contemporânea. Rio de Janeiro: Ed. Lúmen Júris, 2009. 
SILVA, José Afonso da. Aplicabilidade das normas constitucionais. 7. ed. São Paulo: Malheiros, 2008.

SOUZA NETO, Cláudio Pereira. Deliberação Pública, Constitucionalismo e Cooperação Democrática in: SARMENTO, Daniel (Coord). Filosofia e Teoria Constitucional Contemporânea. Rio de Janeiro: Lumen Juris, 2009.

TORRES, Ricardo Lobo. O direito ao mínimo existencial. Rio de Janeiro: Renovar, 2009.

VALLE, Vanice Regina Lírio do. Ativismo Jurisdicional e o Supremo Tribunal Federal. São Paulo: Jiruá, 2009.

VIEIRA, José Ribas; CAMARGO, margarida Maria Lacombe e SILVA, Alexandre Garrido. O Supremo Tribunal Federal como arquiteto constitucional: A judicialização da política e o ativismo judicial. In: Anais do I Forum de Grupos de Pesquisa em Direito Constitucional e Teoria dos Direitos, 2009.

VIEIRA, Oscar Vilhena. Supremocracia. Revista de Direito GV. São Paulo. Jul/dez 2008.

Artigo recebido em: 27/03/2014 Aprovado para publicação em: 07/04/2014

Como citar: MOURA, Emerson Affonso. Judicialização, ativismo e direitos fundamentais: a garantia dos pressupostos essenciais ao processo democrático pelas cortes constitucionais. Revista do Direito Público. Londrina, v.9, n.1, p.227-244, jan./abr.2014. DOI: 10.5433/1980-511X.2014v9 n1p227. 